bioRxiv preprint doi: https://doi.org/10.1101/2021.09.17.460684; this version posted September 17, 2021. The copyright holder for this preprint

(which was not certified by peer review) is the author/funder. All rights reserved. No reuse allowed without permission.

Submitted Manuscript: Confidential

Template revised February 2021

\title{
Title: Kalium rhodopsins: Natural light-gated potassium channels
}

\section{Authors:}

Elena G. Govorunova ${ }^{1}$, Yueyang Gou ${ }^{2,3}$, Oleg A. Sineshchekov ${ }^{1}$, Hai Li ${ }^{1}$, Yumei Wang ${ }^{1}$, Leonid S. Brown ${ }^{4}$, Mingshan Xue ${ }^{2,3,5}$, John L. Spudich ${ }^{1 *}$

\section{Affiliations:}

${ }^{1}$ Center for Membrane Biology, Department of Biochemistry \& Molecular Biology, The University of Texas Health Science Center at Houston McGovern Medical School; Houston, TX 77030, USA.

${ }^{2}$ Department of Neuroscience, Baylor College of Medicine; Houston, TX 77030, USA.

${ }^{3}$ The Cain Foundation Laboratories, Jan and Dan Duncan Neurological Research Institute at Texas Children's Hospital; Houston, Texas 77030, USA.

${ }^{4}$ Department of Physics and Biophysics Interdepartmental Group, University of Guelph; Guelph, Ontario N1G 2W1, Canada.

${ }^{5}$ Department of Molecular \& Human Genetics, Baylor College of Medicine; Houston, TX 77030, USA.

*Corresponding author. Email: John.L.Spudich@uth.tmc.edu

Abstract: We report a family of $\mathrm{K}^{+}$channels, kalium channelrhodopsins (KCRs) from a funguslike protist. Previously known potassium channels, widespread and mainly ligand- or voltagegated, share a conserved pore-forming domain and $\mathrm{K}^{+}$-selectivity filter. KCRs differ in that they are light-gated and they have independently evolved an alternative $\mathrm{K}^{+}$selectivity mechanism. The KCRs are potent, highly selective of $\mathrm{K}^{+}$over $\mathrm{Na}^{+}$, and open in less than 1 millisecond following photoactivation. Their permeability ratio $\mathrm{P}_{\mathrm{K}} / \mathrm{P}_{\mathrm{Na}}$ of $\sim 20$ make KCRs powerful hyperpolarizing tools that suppress excitable cell firing upon illumination, demonstrated here in mouse cortical neurons. KCRs enable specific optogenetic photocontrol of $\mathrm{K}^{+}$gradients promising for the study and potential treatment of potassium channelopathies such as epilepsy, Parkinson's disease, and long-QT syndrome and other cardiac arrhythmias.

One-Sentence Summary: Potassium-selective channelrhodopsins long-sought for optogenetic research and therapy of neurological and cardiac diseases. 
bioRxiv preprint doi: https://doi.org/10.1101/2021.09.17.460684; this version posted September 17, 2021. The copyright holder for this preprint

(which was not certified by peer review) is the author/funder. All rights reserved. No reuse allowed without permission.

Submitted Manuscript: Confidential

Template revised February 2021

Main Text: Potassium $\left(\mathrm{K}^{+}\right)$channels, ubiquitously found in all domains of life are easily recognized by their highly conserved " $\mathrm{K}^{+}$channel signature sequence" (1-4) that encodes a $\mathrm{K}^{+}$selectivity filter that strongly favors conductance of $\mathrm{K}^{+}$over $\mathrm{Na}^{+}$. We report here a type of $\mathrm{K}^{+}$ channel that defines a unique family in that its members (i) completely lack the signature sequence of previously known $\mathrm{K}^{+}$channels, and (ii) unlike prior $\mathrm{K}^{+}$channels, they are channelrhodopsins, retinylidene proteins gated by light.

Channelrhodopsins (ChRs) are light-gated ion channels first discovered in the model chlorophyte alga Chlamydomonas reinhardtii that serve as membrane-depolarizing photoreceptors in phototactic protists (5-7). They are used to manipulate the membrane potential of excitable animal cells with light (optogenetics) (8). Cation conductive ChRs (CCRs) are primarily proton channels, some of which also conduct mono- and divalent metal cations (7, 911). Photoactivation of CCRs depolarizes the neuronal membrane by $\mathrm{Na}^{+}$and $\mathrm{H}^{+}$influx, and stimulates spiking (12). Anion conductive ChRs (ACRs) conduct halides and nitrate (13). Their photoactivation hyperpolarizes or depolarizes the neuronal membrane depending on the electrochemical gradient of $\mathrm{Cl}^{-}$, and inhibits or stimulates spiking, respectively $(14,15)$.

The electrochemical gradient of $\mathrm{K}^{+}$favors membrane hyperpolarization in neurons, which has stimulated efforts to engineer light-gated $\mathrm{K}^{+}$channels to be used as neuronal silencing tools. The $\mathrm{K}^{+} / \mathrm{Na}^{+}$permeability ratio $\left(\mathrm{P}_{\mathrm{K}} / \mathrm{P}_{\mathrm{Na}}\right)$ of $C$. reinhardtii $\mathrm{ChR} 2(C r \mathrm{ChR} 2)$, the most used optogenetic variant, is $0.3-0.5(7,16,17)$. Some mutations increased the $\mathrm{P}_{\mathrm{K}} / \mathrm{P}_{\mathrm{Na}}$ ratio of $C r C h R 2$, but no more than twice (17). Alternatively, $\mathrm{K}^{+}$channels have been modified to become photosensitive by the addition of synthetic photoswitches or photoactive protein domains. Recent results were obtained from fusing the photoreceptor LOV2 domain with a $\mathrm{K}^{+}$channel (18), and indirect control by co-expressing a photosensitive adenylyl cyclase and a cAMP-gated $\mathrm{K}^{+}$ channel $(19,20)$. Both approaches are promising for some applications, but are limited by the slow kinetics of the LOV2/channel chimera (BLINK2) and possible cAMP-induced side effects. Here we show that two ChRs from Hyphochytrium catenoides, which we named HcKCR1 and

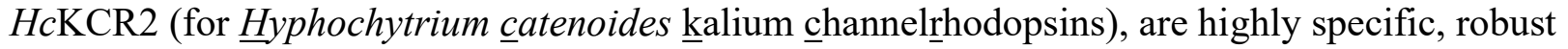
light-gated $\mathrm{K}^{+}$channels that open on the submillisecond time scale.

$H$. catenoides is a fungus-like heterotrophic organism from the stramenopile class Hyphochytriomycetes, the genome of which has been sequenced (21). Two predicted $H$. catenoides proteins show homology to bacteriorhodopsin-like CCRs (BCCRs) from cryptophyte algae (fig. S1). In contrast to other known ChRs, BCCRs contain Asp residues in the positions of the photoactive site (retinylidene Schiff base) proton donor and acceptor of bacteriorhodopsin (Asp85 and Asp96, respectively) (11), conserved in the H. catenoides homologs (fig. S2). A recent high-resolution structure of a Rhodomonas lens BCCR known as ChRmine suggested trimeric organization with a conductive pore between subunits (22). However, out of the residues implicated in the trimer formation in ChRmine, only Glu68 is conserved in the H. catenoides homologs (fig. S2).

We synthesized mammalian-codon adapted versions of the polynucleotides encoding the heptahelical transmembrane (rhodopsin) domains and expressed them in human embryonic kidney (HEK293) cells as mCherry fusions. Both homologs were photoactive; the action spectra of their photocurrents are shown in Fig. 1A. Following a historical convention, we assigned the number 1 to the more red-shifted paralog (spectral maximum $540 \mathrm{~nm}$ ), and the number 2 , to the other (spectral maximum $490 \mathrm{~nm}$ ). 
A series of photocurrents generated by $H c K C R 1$ in response to pulses of continuous light under physiological ionic conditions $\left(130 \mathrm{mM} \mathrm{K}^{+}\right.$in the pipette and $130 \mathrm{mM} \mathrm{Na}^{+}$in the bath, both $\mathrm{pH} 7.4$, for full solution compositions see table S1), is shown in Fig. 1B. The nearly linear current-voltage relationships (IE curves) showed a steep slope with a reversal potential $\left(E_{r e v}\right)$ of $85 \pm 2 \mathrm{mV}$ (mean \pm sem, $\mathrm{n}=10$ cells) (Fig. 1C, red). Such behavior has not been observed in any previously tested ChRs, and could only be explained by selectivity for $\mathrm{K}^{+}$over $\mathrm{Na}^{+}$, as the concentration of $\mathrm{Cl}^{-}$was nearly identical on the two sides of the membrane. This conclusion was confirmed by the shift of the $E_{\text {rev }}$ to $-3 \pm 1 \mathrm{mV}$ (mean \pm sem, $\mathrm{n}=7$ cells) measured upon complete replacement of $\mathrm{Na}^{+}$in the bath with $\mathrm{K}^{+}$(Figs. 1C and D, blue). The corresponding results for $\mathrm{HcKCR} 2$ are shown in fig. S3. The $\mathrm{P}_{\mathrm{K}} / \mathrm{P}_{\mathrm{Na}}$ permeability ratio of $\mathrm{HcKCR} 1$ calculated using the modified Goldman-Hodgkin-Katz (GHK) voltage equation (23) was 23, 60 times greater than that of $C r C h R 2$. The $\mathrm{P}_{\mathrm{K}} / \mathrm{P}_{\mathrm{Na}}$ value of $H c K C R 2$ was 17.

As $H c K C R 1$ exhibited a more red-shifted spectrum, larger current amplitude and higher selectivity for $\mathrm{K}^{+}$than $\mathrm{HcKCR} 2$, we chose this channel for a more detailed characterization. Using a similar procedure as for $\mathrm{Na}^{+}$, we determined the $\mathrm{P}_{\mathrm{X}} / \mathrm{P}_{\mathrm{K}}$ ratios for other metal cations and $N$-methyl- $D$-glucamine $\left(\mathrm{NMDG}^{+}\right)$. Representative series of photocurrent traces and mean $I E$ curves are shown in fig. S4, and the $\mathrm{P}_{\mathrm{X}} / \mathrm{P}_{\mathrm{K}}$ values, in Fig. 1E. The permeability sequence of $H c K C R 1$ was $\mathrm{K}^{+}>\mathrm{Rb}^{+}>\mathrm{Cs}^{+}>\mathrm{Na}^{+}>\mathrm{Li}^{+}>\mathrm{NMDG}^{+} \cong \mathrm{Mg}^{2+} \cong \mathrm{Ca}^{2+}$ (Eisenman sequence IV), the same as that of most voltage- and ligand-gated $\mathrm{K}^{+}$channels (24). To estimate an upper limit of the $\mathrm{P}_{\mathrm{H}} / \mathrm{P}_{\mathrm{K}}$ ratio, we measured the $E_{\text {rev }}$ shift between the bath containing $\mathrm{K}^{+}$at $\mathrm{pH} 9.4$ and nonpermeable $\mathrm{NMDG}^{+}$at $\mathrm{pH} 7.4$ (Fig. $2 \mathrm{~F}$, red). The $\mathrm{P}_{\mathrm{H}} / \mathrm{P}_{\mathrm{K}}$ calculated from this experiment was $\sim 3$ $\times 10^{4}, \sim 80$ times lower than that of $\operatorname{CrChR} 2(7,16,17)$.
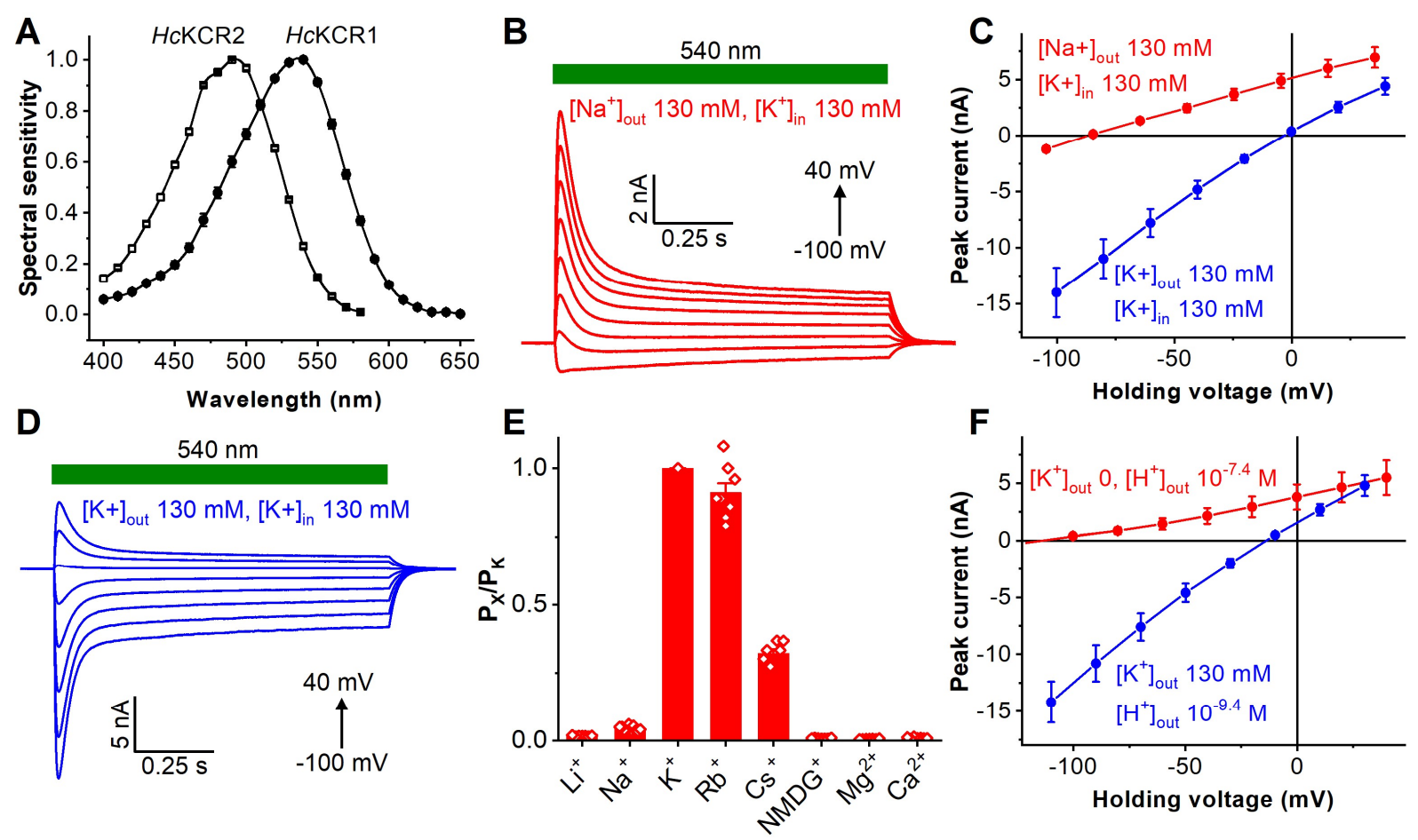

Fig. 1. KCR photocurrents evoked by pulses of continuous light. (A) The action spectra of photocurrents (mean \pm sem, $\mathrm{n}=7$ scans). (B and D) Photocurrents traces recorded from 
bioRxiv preprint doi: https://doi.org/10.1101/2021.09.17.460684; this version posted September 17, 2021. The copyright holder for this preprint

(which was not certified by peer review) is the author/funder. All rights reserved. No reuse allowed without permission.

Submitted Manuscript: Confidential

Template revised February 2021

$H c K C R 1$ in response to 1 -s light pulses upon $20-\mathrm{mV}$ voltage increments. ( $\mathbf{C}$ and $\mathbf{F}$ ) The $I E$ curves (mean \pm sem, $n=7$ cells). (E) The permeability ratios $\left(\mathrm{P}_{\mathrm{X}} / \mathrm{P}_{\mathrm{K}}\right)$; mean $\pm \mathrm{sd}$; the diamonds, the data from individual cells.

We used 6-ns laser flash excitation to follow the kinetics of channel gating, probe for active charge movements and eliminate effects of second photon absorption. Regardless of ionic gradients, channel currents could be fit with three exponentials (Fig. 2A and fig. S5A). Channel opening was biphasic, as in GtACR1 (25) and CrChR2 (26), but channel closing was monophasic, unlike these two ChRs. The fast opening accelerated, and the slow opening slowed upon depolarization (fig. S5B). The $E_{\text {rev }}$ of the amplitudes of the three kinetics components were the same in all experimental conditions (Fig. 2B and fig. S5C). Our interpretation is that the relative permeability for different cations does not change during opening and closing of the channel. With equal concentrations of $\mathrm{K}^{+}$on both sides of the membrane the $E_{\text {rev }}$ depended on bath $\mathrm{pH}$ (Fig. 2C). However, the difference between $\mathrm{pH} 5.4$ and 9.4 was only $\sim 15 \mathrm{mV}$, which confirmed the low $\mathrm{P}_{\mathrm{H}} / \mathrm{P}_{\mathrm{K}}$ of $H c \mathrm{KCR} 1$ relative to earlier known CCRs.

The photocurrent decayed to the noise level in $<200 \mathrm{~ms}$ after the flash. To estimate the time for complete dark recovery we applied a series of laser flashes with progressively shorter intervals between them (fig. S6). The recovery was biphasic with $\tau=0.6$ and $6.6 \mathrm{~s}$ (Fig. 2D). We observed multiphasic recovery with similar $\tau$ values by flash photolysis in both detergentpurified pigment and Pichia membranes (fig. S7).

Absorbance at $430 \mathrm{~nm}$ dropped concomitant with an increase at $395 \mathrm{~nm}$, which indicated that these wavelengths were characteristic of an L-like and an M-like intermediate, respectively (Fig. 2E). Opening of the channel occurred upon transition from the late $\mathrm{L}$ to the early $\mathrm{M}$ intermediate. The $\mathrm{M}$ rise was biphasic, and $\tau$ of the fast component was close to that of channel opening unlike both GtACR1, in which channel opening takes place in the L state $(25,27)$, and "classical" chlorophyte CCRs, in which M rise (i.e. deprotonation of the retinylidene Schiff base) precedes channel opening $(28,29)$.

In previously characterized BCCRs, channel conductance was found to be tightly coupled to active vectorial transport of protons (11). Upon substitution of non-permeable $\mathrm{NMDG}^{+}$for $\mathrm{K}^{+}$ and $\mathrm{Na}^{+}$, photocurrents several times slower than channel current were recorded (Fig. 2F). Their voltage dependence crossed the $\mathrm{X}$ axis at very negative values, characteristic of active charge movement (Fig. 2G). These values remained close even when the difference in the $\mathrm{H}^{+}$gradient was varied over four orders of magnitude (i.e. $240 \mathrm{mV}$ ), suggesting that the photoactive site was barely accessible to protons from outside, as expected from the relatively low proton permeability of $\mathrm{HcKCR} 1$.

The initial unresolved negative component of charge movement is a typical reflection of retinal isomerization, reported earlier in other ChRs (29). Rise of positive photocurrent was biphasic with $\tau$ values similar to those of components of biphasic $\mathrm{M}$ rise, indicating active proton transfer from the Schiff base to an outwardly located acceptor (Fig. 2E, F). However, the peak of the current was reached before that of $\mathrm{M}$ accumulation, and the current decayed in the time window of $\mathrm{M}$ decrease (Fig. $2 \mathrm{H}$ ). This observation suggests that reprotonation of the Schiff base at least partially takes place inside the photoactive site from the initially protonated acceptor, and there is no actual proton pumping across the membrane. In some recordings the decay of active charge movement could be resolved in two exponentials with $\tau=65$ and $420 \mathrm{~ms}$ (Fig. 2F). However, in most cases the two decay components were merged into a single one with $\tau \sim 120$ ms (Fig. 2I and fig. S8). At an increased outwardly directed $\mathrm{H}^{+}$gradient the rates of both positive 
currents only slightly increased (Fig. 2I), which confirmed the isolation of the photoactive site from the outside medium. Such isolation is unusual for $\mathrm{H}^{+}$-pumping rhodopsins and may be related to the high $\mathrm{K}^{+}$selectivity of the $H c \mathrm{KCR} 1$ channel.

A

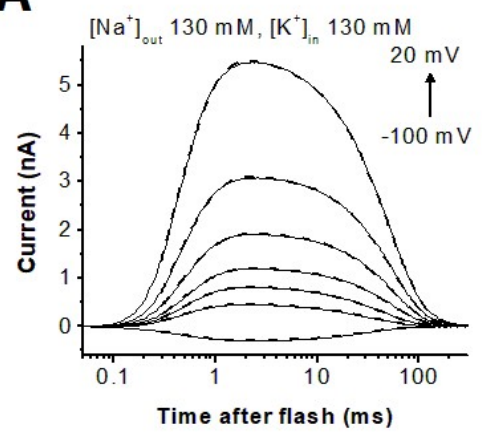

D

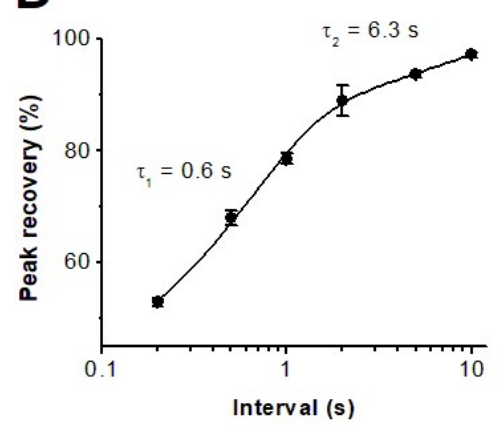

G

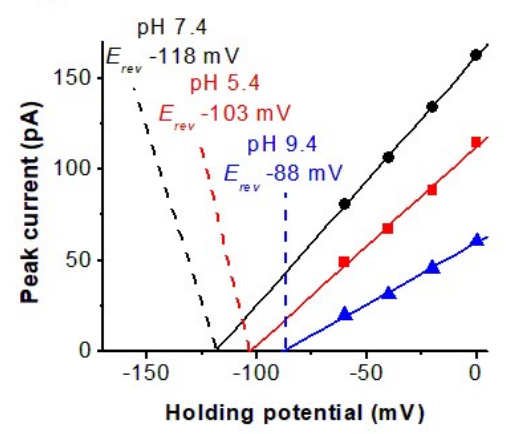

B

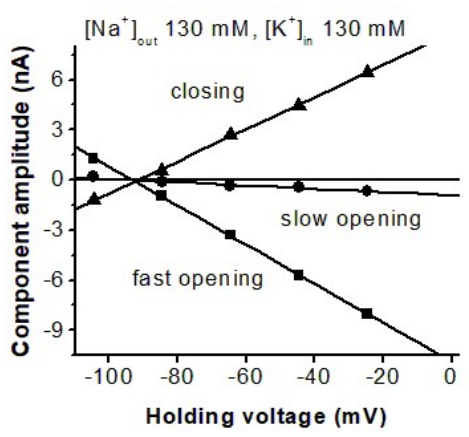

E

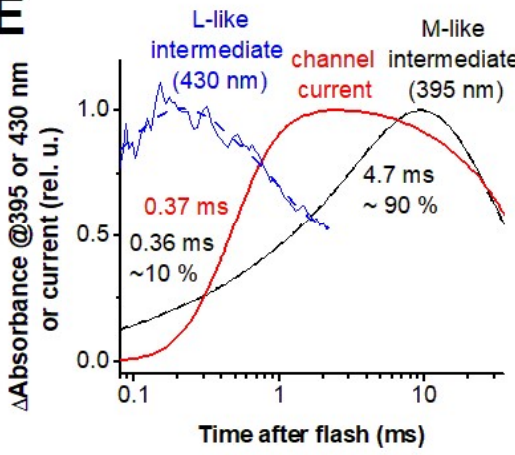

$\mathrm{H}$

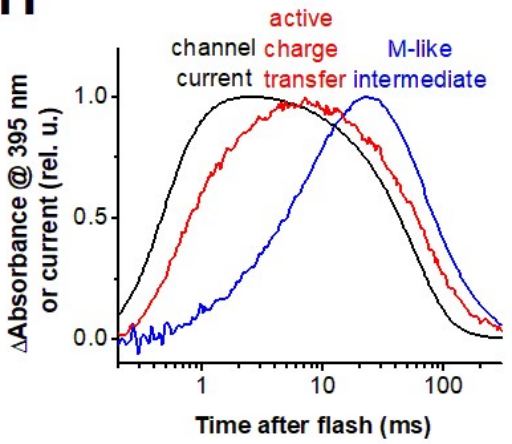

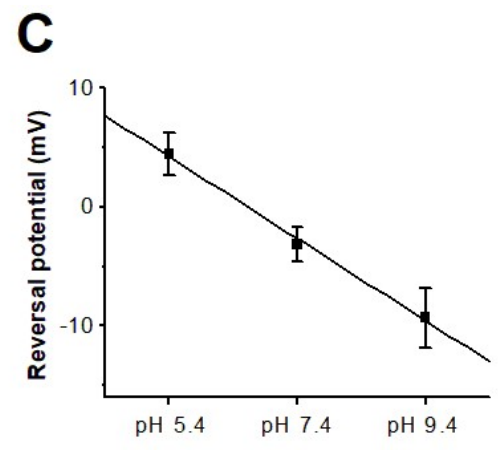

E $\quad\left[\mathrm{NMDG}^{+}\right]_{\text {out }} 130 \mathrm{mM} \mathrm{pH} 7.4$

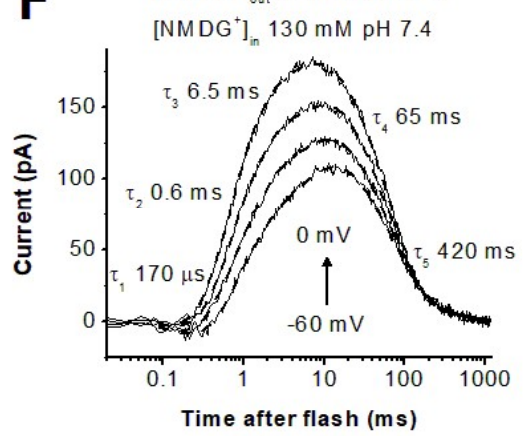

| $\left[\mathrm{NM} \mathrm{DG}^{+}\right]_{\text {out }} 130 \mathrm{mM} \mathrm{pH} 9.4$

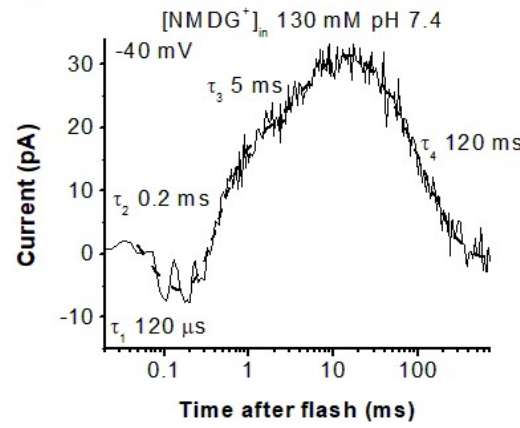

Fig. 2. Photocurrents and photochemical conversion upon single quantum excitation. (A) Photocurrent traces (thin solid lines) recorded from $H c K C R 1$ in response to laser flashes upon $20-\mathrm{mV}$ voltage increments under the indicated ionic conditions superimposed with their multiexponential approximations (dashed lines). (B) Voltage dependence of the three kinetic components of channel currents. (C) Dependence of the channel current $E_{\text {rev }}$ on bath $\mathrm{pH}$ (mean \pm sem, $\mathrm{n}=3-8$ cells). (D) Time course of the peak current recovery (mean \pm sem, $\mathrm{n}=5$ cells). (E) Transient absorbance changes (blue and black) and channel current (red). (F) Photocurrent traces in the absence of permeant metal cations at bath $\mathrm{pH} \mathrm{7.4.} \mathrm{(G)} \mathrm{Voltage} \mathrm{dependence} \mathrm{of} \mathrm{active}$ current at different bath $\mathrm{pH}$. (H) Transient absorbance changes at $400 \mathrm{~nm}$ (blue), compared to 
active and channel currents (red and black, respectively). (I) Photocurrent traces in the absence of permeant metal cations at bath $\mathrm{pH} 9.4$.

We tested whether $H c \mathrm{KCR} 1$ can be used to suppress excitable cell firing. HcKCR1 fused with EYFP and tdTomato were expressed in layer $2 / 3$ pyramidal neurons of the mouse somatosensory cortex by in utero electroporation (Fig. 3A). We prepared acute brain slices from 2-4-week-old mice and performed whole-cell voltage clamp recording from $\mathrm{HcKCR} 1-$ expressing neurons with $142 \mathrm{mM} \mathrm{K}^{+}$in the pipette and $2.5 \mathrm{mM} \mathrm{K}^{+}$in the bath (for full solution compositions see Methods). In response to 1-s pulses of green light, HcKCR1 generated robust photocurrents (Fig. 3B) that recovered quickly in the dark (fig. S9). The decay of photocurrents was best fit by two exponentials with $\tau_{1}=40 \mathrm{~ms}$ (Fig. 3C) and $\tau_{2}=0.6 \pm 0.1 \mathrm{~s}$ at $-45 \mathrm{mV}$ and 0.5 \pm 0.2 at $-85 \mathrm{mV}$ (mean \pm sem, $\mathrm{n}=8$ cells). The ratio of steady-state to peak photocurrents increased when the membrane was hyperpolarized (Fig. 3D). The $I E$ curves showed a reversal potential of $-63 \mathrm{mV}$ for peak photocurrents and $-56 \mathrm{mV}$ for steady-state photocurrents (Fig. 3E$\mathrm{G})$, indicating that channel states formed upon absorption of a second photon under continuous light stimulation alter the relative permeability for cations. We next performed current clamp recordings to test $H c K C R 1$ as a neuronal silencing tool. Photoactivation of HcKCR1 instantly and persistently inhibited all action potentials induced by current injections (Fig. 3H, I), demonstating that $\mathrm{HcKCR} 1$ is a potent optogenetic silencer.

The discovery of KCRs provides an alternative mechanism for $\mathrm{K}^{+}$selection and our studies lay the basis for its elucidation. KCRs also expand the optogenetic toolbox with a natural $\mathrm{K}^{+}$-selective tool that benefits from the high efficiency provided by evolution, enabling direct, rapid, and potent photocontrol of $\mathrm{K}^{+}$transmembrane gradients.
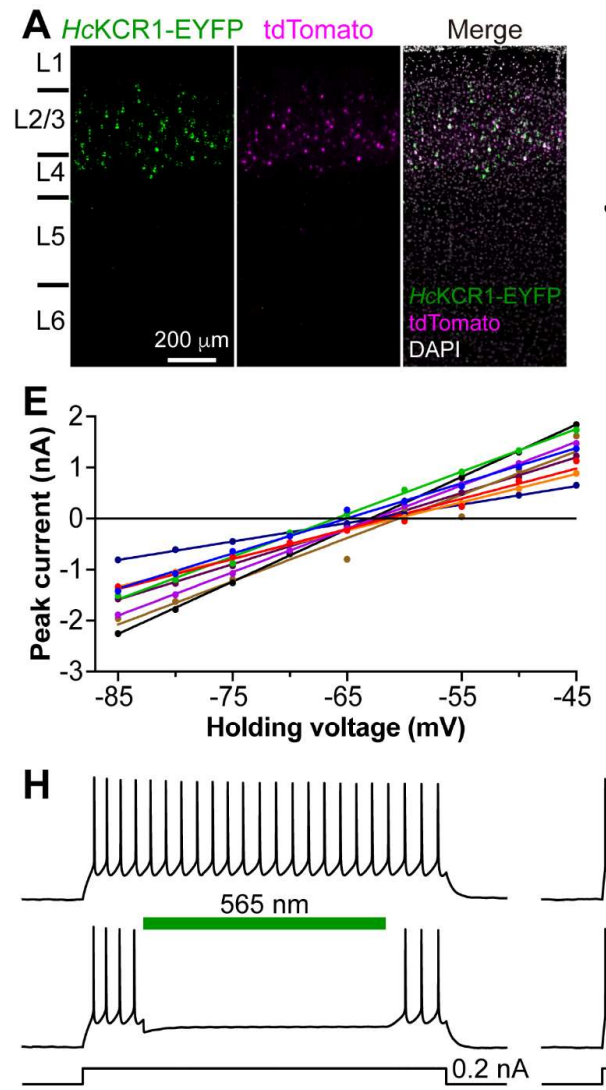

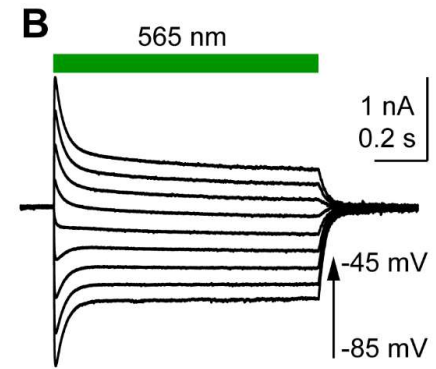

$\mathbf{F}$

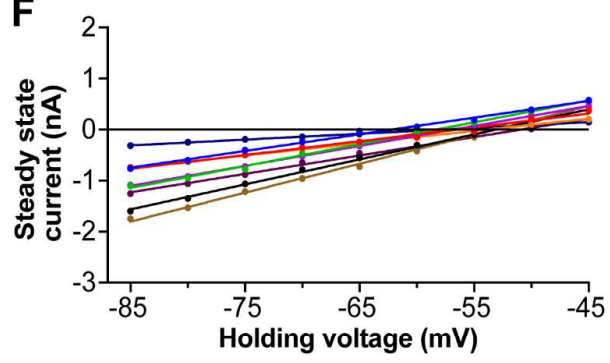

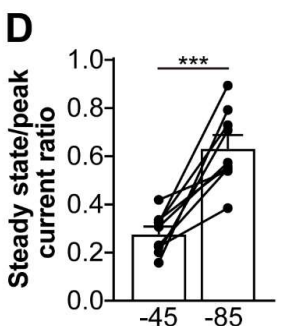

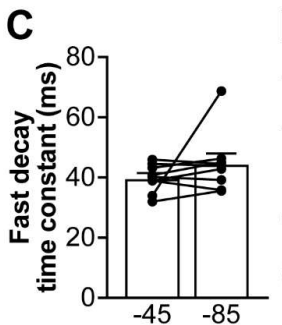

Holding voltage $(\mathrm{mV})$ Holding voltage $(\mathrm{mV})$

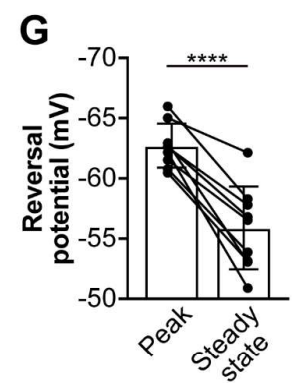

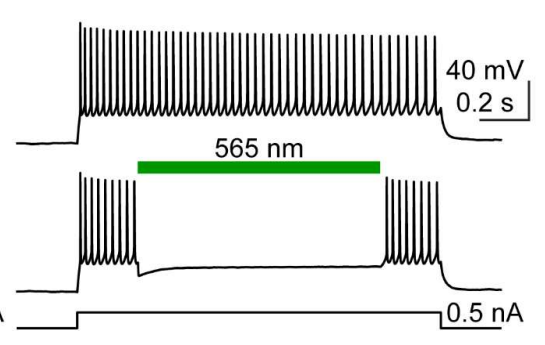

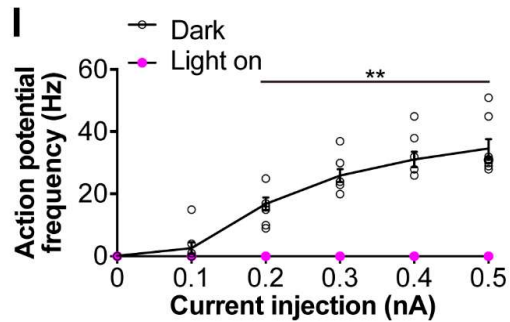


bioRxiv preprint doi: https://doi.org/10.1101/2021.09.17.460684; this version posted September 17, 2021. The copyright holder for this preprint (which was not certified by peer review) is the author/funder. All rights reserved. No reuse allowed without permission.

Submitted Manuscript: Confidential

Template revised February 2021

Fig. 3. Photoactivation of $\mathrm{HcKCR} 1$ in neurons generates robust photocurrents and efficiently suppresses neuronal firing. (A) Fluorescent images of a cortical slice showing $\mathrm{HcKCR} 1-\mathrm{EYFP}$ and tdTomato expression in layer 2/3 neurons. Cortical layers were identified by DAPI staining. L, layer. (B) Photocurrents traces of a $\mathrm{HcKCR} 1$-expressing neuron in response to a 1-s $565 \mathrm{~nm}$ light pulse at holding voltages increased in 5-mV steps. (C) The fast time constant of photocurrent decay at indicated voltages. (D) Ratios of steady-state to peak photocurrents. (E, F) $I E$ curves of peak $(\mathrm{E})$ and steady state $(\mathrm{F})$ photocurrent of individual neurons indicated by different colors. (G) Reversal potentials calculated from the data in E and F. (H) Membrane voltage traces of a HcKCR1-expressing neuron in response to 0.2 (left) and $0.5 \mathrm{nA}$ (right) current injections without (top) and with (bottom) $565 \mathrm{~nm}$ light pulses. (I) The frequencies of action potentials evoked by different current injections with (magenta) and without (black) photoactivation. Data in $\mathrm{C}, \mathrm{D}, \mathrm{G}$ and I are expressed as mean \pm sem, $\mathrm{n}=8$ cells; $* * P<0.01$, *** $P<0.001, * * * * P<0.0001$.

\section{References and Notes}

1. R. MacKinnon, Potassium channels. FEBS Lett. 555, 62-65 (2003).

2. P. Enyedi, G. Czirjak, Molecular background of leak $\mathrm{K}^{+}$currents: two-pore domain potassium channels. Physiol. Rev. 90, 559-605 (2010).

3. T. D. Mackie, J. L. Brodsky, Investigating potassium channels in budding yeast: A genetic sandbox. Genetics 209, 637-650 (2018).

4. A. Mironenko, U. Zachariae, B. L. de Groot, W. Kopec, The persistent question of potassium channel permeation mechanisms. J. Mol. Biol. 433, 167002 (2021).

5. O. A. Sineshchekov, K.-H. Jung, J. L. Spudich, Two rhodopsins mediate phototaxis to low- and high-intensity light in Chlamydomonas reinhardtii. Proc. Natl. Acad. Sci. USA 99, 8689-8694 (2002).

6. G. Nagel et al., Channelrhodopsin-1: a light-gated proton channel in green algae. Science 296, 2395-2398 (2002).

7. G. Nagel et al., Channelrhodopsin-2, a directly light-gated cation-selective membrane channel. Proc. Natl. Acad. Sci. USA 100, 13940-13945 (2003).

8. K. Deisseroth, Optogenetics. Nat. Methods 8, 26-29 (2011).

9. E. G. Govorunova, E. N. Spudich, C. E. Lane, O. A. Sineshchekov, J. L. Spudich, New channelrhodopsin with a red-shifted spectrum and rapid kinetics from Mesostigma viride. mBio 2, e00115-00111 (2011).

10. E. G. Govorunova, O. A. Sineshchekov, H. Li, R. Janz, J. L. Spudich, Characterization of a highly efficient blue-shifted channelrhodopsin from the marine alga Platymonas subcordiformis. J. Biol. Chem. 288, 29911-29922 (2013).

11. O. A. Sineshchekov, E. G. Govorunova, H. Li, J. L. Spudich, Bacteriorhodopsin-like channelrhodopsins: Alternative mechanism for control of cation conductance. Proc. Natl. Acad. Sci. USA 114, E9512-E9519 (2017).

12. E. S. Boyden, F. Zhang, E. Bamberg, G. Nagel, K. Deisseroth, Millisecond-timescale, genetically targeted optical control of neural activity. Nat. Neurosci. 8, 1263-1268 (2005).

13. E. G. Govorunova, O. A. Sineshchekov, X. Liu, R. Janz, J. L. Spudich, Natural lightgated anion channels: A family of microbial rhodopsins for advanced optogenetics. Science 349, 647-650 (2015).

14. M. Mahn, M. Prigge, S. Ron, R. Levy, O. Yizhar, Biophysical constraints of optogenetic inhibition at presynaptic terminals. Nat. Neurosci. 19, 554-556 (2016). 
bioRxiv preprint doi: https://doi.org/10.1101/2021.09.17.460684; this version posted September 17, 2021. The copyright holder for this preprint (which was not certified by peer review) is the author/funder. All rights reserved. No reuse allowed without permission.

Submitted Manuscript: Confidential

Template revised February 2021

15. J. E. Messier, H. Chen, Z. L. Cai, M. Xue, Targeting light-gated chloride channels to neuronal somatodendritic domain reduces their excitatory effect in the axon. eLife 7, e38506 (2018).

16. J. Y. Lin, M. Z. Lin, P. Steinbach, R. Y. Tsien, Characterization of engineered channelrhodopsin variants with improved properties and kinetics. Biophys. J. 96, 18031814 (2009).

17. R. Richards, R. E. Dempski, Re-introduction of transmembrane serine residues reduce the minimum pore diameter of channelrhodopsin-2. PLoS One 7, e50018 (2012).

18. L. Alberio et al., A light-gated potassium channel for sustained neuronal inhibition. Nat Methods 15, 969-976 (2018).

19. S. Beck et al., Synthetic light-activated ion channels for optogenetic activation and inhibition. Front. Neurosci. 12, 643 (2018).

20. Y. A. Bernal Sierra et al., Potassium channel-based optogenetic silencing. Nat. Commun. 9, 4611 (2018).

21. G. Leonard et al., Comparative genomic analysis of the 'pseudofungus' Hyphochytrium catenoides. Open. Biol. 8, (2018).

22. K. E. Kishi et al., Structural basis for channel conduction in the pump-like channelrhodopsin ChRmine. bioRxiv, https://www.biorxiv.org/content/10.1101/2021.1108.1115.456392v456391 (2021).

23. B. Hille, Ion channels of excitable membranes. (Sinauer Associates, Sunderland, MA, 2001).

24. G. Eisenman, H. R, Ionic selectivity revisited: the role of kinetic and equilibrium processes in ion permeation through channels. J. Membr. Biol. 76, 197-225 (1983).

25. O. A. Sineshchekov, E. G. Govorunova, H. Li, J. L. Spudich, Gating mechanisms of a natural anion channelrhodopsin. Proc. Natl. Acad. Sci. USA 112, 14236-14241 (2015).

26. J. Kuhne et al., Unifying photocycle model for light adaptation and temporal evolution of cation conductance in channelrhodopsin-2. Proc. Natl. Acad. Sci. USA 116, 9380-9389 (2019).

27. M. A. Dreier et al., Time-resolved spectroscopic and electrophysiological data reveal insights in the gating mechanism of anion channelrhodopsin. Commun Biol 4, 578 (2021).

28. M. K. Verhoefen et al., The photocycle of channelrhodopsin-2: Ultrafast reaction dynamics and subsequent reaction steps. Chemphyschem 11, 3113-3122 (2010).

29. O. A. Sineshchekov, E. G. Govorunova, J. Wang, H. Li, J. L. Spudich, Intramolecular proton transfer in channelrhodopsins. Biophys. J. 104, 807-817 (2013).

30. M. Baek et al., Accurate prediction of protein structures and interactions using a threetrack neural network. Science, (2021).

31. B. Q. Minh et al., IQ-TREE 2: New models and efficient methods for phylogenetic inference in the genomic era. Mol. Biol. Evol. 37, 1530-1534 (2020).

32. D. T. Hoang, O. Chernomor, A. von Haeseler, B. Q. Minh, L. S. Vinh, UFBoot2: Improving the ultrafast bootstrap approximation. Mol. Biol. Evol. 35, 518-522 (2018).

33. I. Letunic, P. Bork, Interactive Tree Of Life (iTOL) v5: an online tool for phylogenetic tree display and annotation. Nucleic Acids Res. 49, W293-W296 (2021).

34. S. A. Waschuk, A. G. J. Bezerra, L. Shi, L. S. Brown, Leptosphaeria rhodopsin:

Bacteriorhodopsin-like proton pump from a eukaryote. Proc. Natl. Acad. Sci. USA 102, 6879-6883 (2005).

35. M. Xue, B. V. Atallah, M. Scanziani, Equalizing excitation-inhibition ratios across visual cortical neurons. Nature 511, 596-600 (2014). 
36. E. G. Govorunova et al., Cation and anion channelrhodopsins: Sequence motifs and taxonomic distribution. MBio 12, e0165621 (2021).

\title{
Acknowledgments:
}

\section{Funding:}

National Institutes of Health grants R35GM140838 (JLS) and U01NS118288 (MX, JLS)

Robert A. Welch Foundation Endowed Chair AU-0009 (JLS)

Natural Sciences and Engineering Research Council of Canada Discovery Grant RGPIN2018-04397 (LSB)

\section{Author contributions:}

Conceptualization: EGG, OAS, LSB, MX, JLS

Methodology: EGG, OAS, LSB, MX, JLS

Investigation: EGG, YG, OAS, HL, YW, LSB

Visualization: EGG, YG, OAS

Funding acquisition: LSB, MX, JLS

Project administration: JLS

Supervision: JLS

Writing - original draft: EGG, YG, OAS, MX, JLS

Writing - review \& editing: EGG, YG, OAS, HL, YW, LSB, MX, JLS

Competing interests: Authors declare that they have no competing interests.

Data and materials availability: All data and materials are available to any researcher upon a reasonable request, pending materials transfer agreements (MTAs). The sequences of $\mathrm{HcKCR} 1$ and $\mathrm{HcKCR} 2$ expression constructs are available from GenBank (accession numbers MZ826862 and MZ826861, respectively).

\section{Supplementary Materials}

\author{
Materials and Methods
}

Figs. S1 to S9

Table S1

References (30-36) 